\title{
DIDÁTICA E EPISTEMOLOGIA DA EDUCAÇÃO BÁSICA BRASILEIRA: CRÍTICAS E PROPOSTAS
}

\author{
DIDACTICS AND EPISTEMOLOGY OF THE BRAZILIAN BASIC EDUCATION: CRITICISM AND \\ PROPOSALS
}
DIDÁCTICA Y EPISTEMOLOGÍA DE LA EDUCACIÓN BÁSICA BRASILEÑA: CRÍTICAS Y PROPUESTAS

\author{
Renato Kraide Soffner \\ Pesquisador e professor permanente do PPGE - UNISAL \\ E-mail: renato.soffner@am.unisal.br
}

\begin{abstract}
RESUMO
Apresenta-se uma reflexão sobre as práticas didáticas da Educação Básica brasileira, criticando o modelo prescritivo, conteudista e reducionista das mesmas. Assumimos as angústias dos profissionais da Educação Básica, em seu anseio por auxílio objetivo e suporte metodológico a serem providos pela pesquisa em educação. Nossa hipótese de trabalho indica que tal pesquisa, e também a formação de professores, deveriam prover métodos e práticas que gerassem resultados reais suficientes para justificar todo o investimento feito em investigação educativa no Brasil. Concluímos que apenas as inovações pedagógicas com bases teóricas poderão auxiliar no processo de construção de verdadeira práxis educativa, e mostramos alguns caminhos e propostas.
\end{abstract}

PALAVRAS-CHAVE: Didática. Epistemologia. Educação Básica.

\section{ABSTRACT}

This work presents a reflection on the teaching practices of the brazilian basic education, criticizing the prescriptive and reductionist model. We assume the anguish of the professionals of basic education, in its longing for objective and methodological support to be provided by educational research. Our working hypothesis indicates that such research, and even the teacher training, should provide methods and practices that generate enough real results to justify all the investment made in educational research in Brazil. We conclude that only pedagogical innovations with theoretical bases may assist in the process of building true educational praxis, showing some paths and proposals.

KEYWORDS: Didactics. Epistemology. Basic Education.

\section{RESUMEN}

Se presenta una reflexión sobre las prácticas didácticas de la educación básica brasileña, criticando el modelo preceptivo, oral y reduccionista de los mismos. Asumimos la angustia de los profesionales de la educación básica, en su anhelo de ayuda objetiva y apoyo metodológico para que sean proporcionados por la investigación en educación. Nuestra hipótesis de trabajo indica que tal investigación, así como la formación de docentes, deben proporcionar métodos y prácticas que generen suficientes resultados reales para justificar toda la inversión en investigación educativa en Brasil. Concluimos que sólo las innovaciones pedagógicas con bases teóricas pueden ayudar en el proceso de construir verdadera praxis educativa, y mostramos algunos caminos y propuestas.

PALABRAS-CLAVE: Didáctica. Epistemología. Educación básica. 


\section{INTRODUÇÃ̃O}

A palavra educação tem sua origem etimológica no latim "e-dúcere” (trazer para fora) e, também, em "educare" (cuidar, tomar conta). Eis o real papel do educador, em suas bases históricas e filosóficas: aquele que traz o educando para fora da escuridão, e que cuida dele. De Platão a Locke, de Rousseau a Dewey ou Freire, educação certamente não é doutrinação. Não é meio, mas fim. Embora os fins propostos sejam atingidos pelos meios disponíveis. É essa a essência e magnificência do trabalho docente, aqui discutida do ponto de vista da didática e da epistemologia.

A preocupação com as práticas educativas e o desempenho da Educação Básica no Brasil, na atualidade, é fato decisivo e comprovado. A COORDENAÇÃO DE APERFEIÇOAMENTO DE PESSOAL DE NÍVEL SUPERIOR (CAPES, 2011), responsável pela integração entre o Ensino Superior e a Educação Básica ${ }^{1}$, indicou em relatório comemorativo dos 60 anos da entidade que "o principal desafio da Educação Básica brasileira, sobre o qual a Capes começou a se debruçar a partir das mudanças foi a deficiência de formação dos professores que atuam nas escolas públicas do país” (CAPES, 2011, p. 17). O relatório comenta que existe, mesmo, a situação em que professores sem nem mesmo a graduação estarem atuando em sala de aula, por absoluta falta de recursos humanos qualificados.

Queremos, aqui, levantar a fragilidade que tal situação pode causar nas questões da epistemologia e da didática do professor. Se não há bases teóricas de formação, não há prática efetiva e responsável, muito menos práxis. O tradicional modelo prescritivo, conteudista e reducionista se perpetua em nossa educação, em especial nas práticas didáticas, com graves consequências junto aos processos de avaliação e ao cotidiano metodológico do professor, afetando os métodos e as técnicas de ensino.

É visível o mal-estar permanente que apresentam nossos professores da base educativa escolar e formal, quando anseiam por real aplicação de tudo o que a pesquisa em educação gera, muitas vezes suportada por fomento oficial. Os resultados da investigação

\footnotetext{
${ }^{1}$ Desde a Lei n. ${ }^{\circ} 11.502 / 2007$, a CAPES teve suas competências modificadas: além de coordenar o alto padrão do Sistema Nacional de Pós-Graduação brasileiro, passa a induzir e fomentar a formação inicial e continuada de professores para a Educação Básica do país. Ações como o PARFOR (Plano Nacional de Formação dos Professores da Educação Básica), a Universidade Aberta do Brasil e a bolsa PIBID (Programa Institucional de Iniciação à Docência) buscam o incremento no número de professores e a formação continuada dos mesmos, com o objetivo maior de melhoria da Educação Básica.
}

\begin{tabular}{l|l|l|l|l|} 
(C) Rev. Triang. & Uberaba, $\mathrm{MG}$ & $\mathrm{v} .11$ & $\mathrm{n} .2$ & p. $91-106$
\end{tabular}


científica em educação deveriam, de fato, prover métodos e práticas inovadores para o cotidiano do professor. Fala-se muito em práxis educativa, mas muito pouco se oferece para que o professor atinja, de verdade, tal conceito em sua prática.

\section{A EPISTEMOLOGIA DO PROFESSOR}

Continuamos sem saber o que um professor faz - quando ensina, e como o aluno aprende - quando está sendo ensinado. Isto levanta sérias questões pedagógicas e epistemológicas, ainda mais quando se discute o papel da didática moderna nos processos de aprendizagem da Educação Básica (ERNELING, 2010). Saviani (2008) apresenta a hipótese de que os professores sofrem de uma insuficiência teórica que lhes daria sustentação para não serem vítimas de flutuações pedagógicas ou modismos que impedem a formação de verdadeiro espírito crítico.

Desde Piaget (1973) já sabíamos que o conhecimento não pode ser concebido como algo predeterminado nas estruturas internas do sujeito, pois que resultam de uma construção efetiva e contínua. E nem mesmo nas características preexistentes no objeto, pois que só são conhecidos graças à mediação necessária dessas estruturas pelo sujeito do conhecimento. Este resulta de interações que se produzem a meio caminho entre o sujeito e o objeto, dependendo dos dois, mas decorrente de uma indiferenciação completa, e não de intercâmbio entre formas distintas.

Tais concepções mais teóricas, que chamaremos de epistemologias do ensino e da aprendizagem, com o sentido de estudo das passagens do conhecimento de níveis inferiores para superiores - ou conhecimento científico, como queria Piaget, parecem ser desconhecidas de grande parte dos educadores da Educação Básica. E isso afeta gravemente sua prática educativa.

As epistemologias podem ser classificadas em três grandes grupos (BECKER, 1993) a citar:
a) Epistemologias empiristas.
b) Epistemologias aprioristas.
c) Epistemologias construtivistas. 
Segundo a visão empírica, a mente humana assimila as experiências do sujeito e preenche um vazio, quando o processo de ensinar e de aprender é centrado na figura do professor.

Já a visão apriorista (ou inatista) afirma que o conhecimento é elemento intelectual, que tem origem nas ideias e não na experiência do sujeito, sendo que este apresenta capacidade inata de aprender, que pode ser facilmente confundida com uma alegada “independência intelectual” do aluno, espécie de capacidade auto didática.

Finalmente, no enfoque construtivista o professor é mediador entre um sujeito que aprende e um conteúdo (objeto) que deve ser aprendido, e torna-se auxílio ao processo de aprendizagem, que confere suporte para que o aprendente siga adiante em sua missão de aprender. É processo ativo de relação entre o sujeito e o meio, pelas vias da assimilação e da acomodação propostas por Piaget, que levam à real construção do novo conhecimento.

Tais concepções sobre a construção do conhecimento, se dominadas pelo professor, afetam sua prática docente (BECKER, 2003), mesmo que não tenha, em geral, consciência do fato. A epistemologia influencia, portanto, a didática. Das noções que o professor precisa ter sobre a dimensão epistemológica, citamos a relação entre o concreto e o abstrato, e o objetivo versus o subjetivo.

Da mesma forma que o fizemos linhas atrás, Becker (2003) apresenta duas concepções epistemológicas de interesse para esta discussão: o inatismo (que se refere à vocação do aluno), em oposição ao empirismo (ser humano nascido como tábula rasa). Ambas demonstram uma passividade do sujeito no processo, em oposição à Epistemologia Genética de Piaget, na qual a ação do sujeito é fundamental para a aprendizagem, já que é essa ação quem gera estruturas cognitivas sucessivas, independentes da bagagem hereditária, o que mostra uma capacidade de aprender da espécie humana, e não do indivíduo. A herança genética, traduzida por um sem-número de características individuais (genótipo único), vai interagir com o meio (fenótipo único) provando que não há lugar para padrões em educação e pedagogia, já que cada indivíduo é fruto de uma combinação genótipo-fenótipo única.

Também Becker (1993), demonstrou que o modelo de transmissão de informação do professor para o aluno, que às vezes privilegia o papel do professor pode também desviar o foco para o papel do aluno. 
A relação entre a epistemologia professada pelo professor e a pedagogia correspondente é mostrada por Becker (1993) em termos de ser o empirismo associado a uma pedagogia diretiva, o apriorismo a uma pedagogia não diretiva, e o construtivismo a uma pedagogia relacional.

Podemos indicar como necessidades didáticas e epistemológicas do professor, a partir de tal realidade, o entendimento de psicologia educacional, e mesmo de pedagogia mais inovadora. Não existe a mágica de receitas prontas do cotidiano do ensino, como o querem, muitas vezes, produtores de material didático para o uso do professor (que se tornam amplamente disponíveis, atualmente, mesmo no ambiente da educação pública). O reducionismo epistemológico de que o sujeito não age porque o meio tudo lhe dá (na concepção empirista) ou que o sujeito não age porque tudo herdou (na concepção apriorista) não pode ter relação com os fins da educação.

Lembremos que o ensino não garante a aprendizagem. Assim, o professor deve constantemente inventar situações e ambientes experimentais para facilitar a construção de conhecimento pelo seu aluno. Mas também nos lembremos de que o excesso de liberdade pedagógica vai favorecer, igualmente, uma prática educativa não desejada.

A escola atual não parece preocupada em encontrar respostas para esse tipo de questão de formação e prática do professor da Educação Básica. O modelo conteúdo-ensinoprofessor, paradigma da escola tradicional, e que prevalece até hoje, não está certamente em vias de extinção, ou mesmo de evolução. Para isso, seria preciso que toda a comunidade envolvida no processo educacional iniciasse um debate e uma análise de base sobre as estruturas que compõem a educação formal tradicional, da perspectiva da filosofia da educação de cunho epistemológico. A maioria dos profissionais da Educação Básica não parece pronta para essa tarefa, pois exige que se abandonem pré-conceitos arraigados, frutos de uma educação que foi desenhada num modelo industrial, de forte conotação política e ideológica, para a formação de indivíduos padronizados em termos de conhecimentos e comportamentos. 


\section{MARCO TEÓRICO}

Busquemos agora fundamentação teórica para a discussão. Para Morin (1996, p. 60), ainda hoje a elucidação da natureza da aprendizagem está submetida a uma alternativa mutilante entre um inatismo segundo o qual “[...] só se aprende o que já se conhecia” e de um aquisicionismo segundo o qual "[...] só a experiência nos instrui”.

De acordo com Popper (2001), as questões do conhecimento inato no animal em oposição ao conhecimento adquirido pela aprendizagem ativa geram dificuldades e problemas conceituais, mas conduzem a experiências e à aprendizagem do novo, que é campo de atuação da própria pesquisa. Do ponto de vista do inato, o autor cita o trabalho de Konrad Lorenz, que defendia a internalização do conhecimento na carga genética do animal, numa condição declarada de apriorismo.

Mas Popper defende a visão de que tudo o que conhecemos é geneticamente a priori, pois que o a posteriori é seleção daquilo que nós próprios inventamos de forma incipiente. $\mathrm{Na}$ verdade, Popper defende que todo conhecimento é a priori por ser hipotético ou conjectural - baseado em hipóteses. E é a eliminação de hipóteses, a posteriori, que gera o conflito entre as mesmas e a realidade (POPPER, 2001, p. 71). É nisso que consistiria a componente empírica do nosso conhecimento, suficiente para nos permitir aprender com a experiência, para que sejamos, também, empiristas - aprendendo por tentativa e erro, dentro de nossa vivência no mundo.

Polanyi $(1974 ; 2009)$ defende o conhecimento tácito como nova proposição ao debate entre o inato e o construído. Para o autor, sabemos mais do que podemos expressar - a maior parte do nosso conhecimento é tácito. Este não pode ser facilmente formalizado e colocado em palavras, ao tentar ser explicado. É, para o autor, a base de nosso conhecimento do mundo. Já o conhecimento que pode ser formalizado, explicado, é chamado, por Polanyi (1974), de conhecimento explícito. Em outros idiomas é importante a questão do "conhecer o que" e o "conhecer como": em Inglês - knowing what e knowing how; no Alemão o wissen e o können.

Utilizamos nosso corpo para conhecer o mundo, e é pelo uso inteligente do nosso corpo que nos sentimos tendo um corpo, alheio ao mundo concreto exterior. Aqui temos uma conexão com Piaget, que defende a visão de que construir conhecimentos é agir sobre o objeto, e transformá-lo nesse processo. Quando agimos na dimensão tácita, estamos 
incorporando algo em nosso próprio corpo, ou expandindo nosso corpo para inclui-lo, para que possamos nele habitar. De nada adianta observar algo a fim de se aprender sobre ele, é preciso vivê-lo. É o que Polanyi (1974) chama de interiorização.

Nossa educação escolar se pauta demasiadamente no ensino justamente por desconsiderar os demais papéis dela mesma, que são a pesquisa e a extensão. É natural, portanto, que a maior parte dos esforços e da energia (além dos conflitos e da dialética do cotidiano escolar) surja nas questões de didática e ensino (BORDENAVE e PEREIRA, 1986), ficando a epistemologia e as preocupações com a construção de conhecimentos em segundo plano. Estes autores diferenciam os tipos de educação "bancária" - proposta por Paulo Freire (FREIRE, 1983) - conteudista, baseada na experiência do professor e na memorização estéril de conceitos abstratos, tornando o aluno um agente passivo do processo e a problematizadora ou libertadora - participação ativa na solução de problemas, desafiadora para o aluno, de diálogo com o professor, com teorização e hipótese a partir da observação do problema e da realidade. A aprendizagem é pesquisa em que o aluno passa de uma visão global do problema a uma visão analítica do mesmo, por meio de sua teorização, para chegar a uma síntese provisória, equivalente à compreensão. Nascem hipóteses de solução, da compreensão profunda do problema e de suas consequências, que obrigam à seleção das soluções mais viáveis. A síntese tem continuidade na práxis, ou seja, na atividade transformadora da realidade.

Para Bordenave e Pereira (1986), são problemas clássicos da educação:

- Um ensino deficiente, em geral, e um professor sem ideias sobre como melhorá-lo;

- A personalidade do aluno que não é conhecida nem respeitada;

- A falta de uma formação pedagógica docente eficaz, que afete o ensino e a aprendizagem pelo aluno;

- Os problemas no planejamento das disciplinas (formalidades que não se cumprem no cotidiano);

- A participação pouco ativa dos alunos na aula, denunciada por Paulo Freire (1983) como sendo falta de dialogicidade;

- Os problemas de comunicação em aula; 
- A falta de pesquisa e de pensamento científico (pois aprender é, antes de tudo, pesquisar);

- A fragilidade das avaliações na aferição da aprendizagem real;

- As barreiras à inovação no ensino e na aprendizagem.

Algumas considerações se fazem presentes:

- A aprendizagem é processo, e não produto; mas só podemos avaliá-la indiretamente, por meio dos produtos gerados pelos aprendentes e por seu desempenho;

- A aprendizagem gera mudança no conhecimento, nas crenças, nas atitudes e no comportamento dos alunos; mas é bastante difícil medi-la;

- A aprendizagem não é algo feito aos alunos, mas algo que eles mesmos fazem; e aqui existem fatores individuais a serem considerados, como defendem as teorias de aprendizagem mais ativas;

- A aprendizagem não é guiada apenas por fatores pedagógicos, mas também por indicadores sociais, emocionais e motivacionais, o que dificulta sua medição.

Ainda na Pedagogia do Oprimido, Paulo Freire (1983) sinalizava os desvios didáticos, metodológicos e epistemológicos de nossa educação - não trabalhamos os conteúdos, simplesmente forçamos os alunos a memorizá-lo. Fazemos o discurso da democratização da escola (teoria), mas na prática continuamos autoritários, o que gera uma inconsistência entre o que falamos e o que fazemos; ou seja, o chavão de que na prática a teoria é diferente, o que importa é o que faço, não o que falo. E isso tem raiz ideológica, tanto que é preciso convencer o educador a mudar seu ponto de vista - não adianta forçá-lo a tal.

Para Freire (1983), existe larga diferença entre o professor e o educador: a distância entre a teoria e a prática costuma ser visível, pois falta compreensão da diferença entre elas (consiste, de fato, numa relação contraditória, processual, dialética, tensa, e para Freire tem a ver com a própria formação autoritária da sociedade brasileira). Não há boa teoria que não seja prática, e não há prática sem a compreensão profunda de que ensinar não é fazer o discurso sobre o perfil do conteúdo, mas fazer com que o aluno se envolva de forma integral ao processo. 
Em termos gnosiológicos e epistemológicos, da relação do sujeito com o objeto do conhecimento, não existe para Freire (1983), na verdade, prática pedagógica sem conteúdo, pois que este é o objeto do conhecimento escolar, na busca, entretanto, da formação maior provida pelo processo educativo.

\section{ALGUMAS PREMISSAS CRÍTICAS SOBRE DIDÁTICA: EM BUSCA DA AUTONOMIA}

Ensinar não é apenas transferir para os alunos o conteúdo dominado pelo professor: é tarefa complexa de comunicação e motivação, e muito mais do que o simples ensinar de fatos, teorias e métodos. A atividade docente deveria capacitar para o pensamento racional e crítico (capacidade de reflexão), para a solução de problemas reais, para a tomada de decisões importantes, para a motivação em relação à aprendizagem permanente e para a responsabilidade individual e social. E o aluno deveria sair da escola com uma sólida capacidade de avaliação crítica da informação disponível, a fim de construir conhecimentos de ampla aplicação em sua vida pessoal e profissional. À totalidade desses desenvolvimentos podemos chamar autonomia do aprendente.

Apresentaremos agora subsídios para tal concepção didática.

Para Bruer (1993), a aprendizagem depende de conhecimento anterior, pois os aprendentes constroem ativamente o entendimento pela seleção entre a experiência atual da aula com os esquemas preexistentes, armazenados na memória de longo prazo - note-se aqui uma referência direta às ideias de Piaget. Assim, de nada adianta considerar apenas a ação docente, como o faz a didática tradicional.

Brooks (1997) propõe princípios didáticos e pedagógicos que possam dar suporte ao modelo construtivista de conhecimento:

- Problemas de relevância devem ser empregados em aula;

- A aprendizagem deve se dar em torno de grandes ideias (quais sejam, os conceitos primários);

- Há que se valorizar a visão do aluno, e não apenas a do professor;

- A avaliação de aprendizagem deve ser conduzida no contexto do que foi efetivamente ensinado. 
A função do professor seria, portanto, a de inventar situações experimentais para facilitar a aprendizagem de seu aluno. É clássica a afirmação de Piaget de que cada vez que se ensina prematuramente a uma criança alguma coisa que ela poderia ter descoberto por si mesma, essa criança foi impedida de descobrir e, consequentemente, de entender as coisas de forma mais completa (PIAGET, 1975).

Para Vigotski (2007), em sua teoria sociocultural dos processos psicológicos superiores, o mecanismo de mudança individual ao longo do desenvolvimento tem sua raiz na sociedade e na cultura, pela internalização dos sistemas de signos (linguagem, escrita, sistema numérico); as funções psicológicas superiores são mediadas e dialéticas, e apresentam extrema importância na fala e na atividade prática (inteligência prática e abstrata, pelo uso de instrumentos de forma inteligente). A Zona de Desenvolvimento Proximal (ZDP) mostra o nível de desenvolvimento real (funções mentais das crianças completadas, independente de problemas) em oposição ao nível de desenvolvimento potencial (solução de problemas sob a orientação de adultos ou em colaboração com colegas mais capazes), e isto precisa ser considerado pelo professor em atividade no cotidiano da sala de aula. Também o brincar é avanço na fase de desenvolvimento, uma forma de viver o futuro, pelo lúdico e pelos jogos. E completa que o simples "observar e fazer" não resolve o problema pedagógico, a abstração é importante (como em PIAGET, 1975).

E para que essas propostas possam ser implementadas, deve o professor apresentar algumas habilidades específicas, que veremos a seguir.

\section{COMPETÊNCIAS DO PROFESSOR}

Para Perrenoud (2000), o professor competente em sua atividade pedagógica deve organizar e dirigir situações de aprendizagem, conhecer conteúdos e traduzi-los em objetivos de aprendizagem, considerar as representações dos alunos, considerar erros, elaborar a sequência didática e de emprego de recursos, e valorizar as atividades de pesquisa.

Deve, ainda, administrar a progressão das aprendizagens, de situações-problema, numa visão longitudinal dos objetivos de ensino e da relação com as teorias subjacentes; observar e avaliar seus alunos em situação de aprendizagem, e gerar um balanço periódico de 
competências e de progressão; conceber dispositivos de diferenciação, para a administração da heterogeneidade e das dificuldades de aprendizagem, integrando os alunos em suas diversas especificidades.

O autor cita ainda como competências do professor contemporâneo: o envolvimento dos alunos em seu próprio trabalho docente, incrementando o desejo de aprender; a realização do projeto pessoal do aluno, e do trabalho em equipe; a participação na administração da escola, envolvendo os pais; o emprego das novas tecnologias de informação e de comunicação (educação a distância, simulações, multimídia, redes).

O professor deve também considerar os deveres e dilemas éticos da profissão, e a administração da própria formação continuada.

Para Perrenoud (1998) competência é conjunto de recursos que mobilizamos para agir (e não apenas os saberes eruditos) e a capacidade de agir eficazmente em determinado tipo de situação. Fala-se bastante de competências do aprendente em grande parte dos debates educacionais e pedagógicos. Mas o que temos a dizer sobre as habilidades exigidas do docente, em especial num mundo de mudanças constantes e de paradigmas contrastantes com o que costuma ser estável em termos de modelos educativos?

\section{PROPOSTA DE UM AMBIENTE DE AULA CRIATIVO: DIDÁTICA INOVADORA}

Apresentaremos agora algumas propostas para a melhoria de tudo o que foi aqui criticado, como forma de suporte às expectativas do professor. Já afirmamos que o mesmo aguarda o auxílio da pesquisa em educação para melhorar os processos educativos de seu cotidiano.

Do ponto de vista físico e ambiental, o professor deve contar com infraestrutura de tecnologia de informação e comunicação adequada, baseada em dispositivos digitais que permitam o acesso a redes sociais de aprendizagem colaborativa. O conteúdo e o currículo devem ser baseados em atividades realmente significativas para o aluno, podendo o professor tirar proveito dos recursos abertos que o emprego de tecnologia permite - um tipo de rigor intelectual - ou "hard fun", como o definiu Papert (1980): desafio e esforço - mas mediados, interessantes, motivadores (aqui se apresenta o aspecto afetivo pela atividade). Também a formalização e a experimentação (o fazer científico) terão seu papel a cumprir. 
As estratégias de aprendizagem terão base teórica adequada, de forma a se evitar o "bom senso pragmático" já criticado anteriormente neste trabalho, e permitindo que o professor declare uma epistemologia de forma consciente.

Atividades inovadoras devem ser testadas, como o emprego da exploração de temas específicos, da criação de ambientes próprios de aprendizagem, de jogos, de personalização, de colaboração, de modelagem e de simulações. Uma aula tradicional deverá tratar da formação de conceitos pela teoria e pela abstração. O problema a se considerar é a situação em que o aluno não tem ainda as estruturas formadas para assimilar o novo conteúdo (como exemplos, a idade e a origem sociocultural e pedagógica, sem dizer das dificuldades psicopedagógicas). As práticas didáticas e de ensino utilizarão recursos de pensamento crítico, criativo e estratégico no aluno (SOFFNER, 2007).

Como argumenta Lowman (1995), até que ponto aprender é função específica e condicionada do ensinar? Até que ponto podemos avaliar o ensino com base no que o aluno aprende? Existe, certamente, a fricção entre teoria e prática, entre o abstrato e o concreto; o professor conteudista e expositivo, que considera o processo educativo como mera transmissão de informação e de saberes, desconsidera que os alunos não são os seres ideais, homogêneos e motivados previstos nos compêndios pedagógicos. $\mathrm{O}$ aluno aprende, na verdade, pela relação entre a dimensão subjetiva e o mundo concreto, mas mediados pelo professor.

\section{EM BUSCA DA PRÁXIS - PROPOSTAS}

Além dos fatos didáticos e pedagógicos já discutidos, do ponto de vista do professor, é fato reconhecido que a nova geração de aprendentes possui características únicas a serem consideradas no processo educativo (TAPSCOTT, 1998; VENN e VRAKKING, 2009).

Faremos agora algumas propostas de contribuição ao tema, considerando tudo o que aqui foi discutido em termos de pesquisa em educação, como instrumento de melhoria dos processos didáticos da Educação Básica.

Para Christensen (2009), algumas alternativas de incremento dos níveis de aprendizagem podem ser obtidas na utilização da indução, da dedução e do entendimento dos conceitos de correlação e de causalidade no ensino. Para o autor, há que se empregar bem 
mais estatística a matemática de forma aplicada e facilitadora da compreensão de problemas pela manipulação de dados e de informação. Também a pesquisa é excelente mecanismo de construção de conhecimento, visto ser ação do sujeito que tenta entender o objeto em estudo, considerando conhecimentos já estabelecidos sobre o fenômeno ou fato. O papel do papel do professor, neste caso, é criar situações que possibilitem a invenção e explicação dos fenômenos estudados - diferente do mero treinamento, onde o aprendiz atua sem compreender, com ausência do processo reflexivo, agindo de forma prática e sem a preocupação com os aspectos e justificativas teóricos.

Segundo Lowman (1995), a sala de aula é uma arena interpessoal onde se trava uma batalha de interesses diversos. E vem daí a necessidade de preparo do professor para sua atuação maior, em classe. Para o autor, o bom professor é aquele que aprende a falar diante de uma classe ou grupo; que promove relacionamentos motivadores com os estudantes; e que enriquece a experiência de sala de aula com o uso de recursos alternativos, além dos tradicionais bem utilizados.

Também o lúdico (jogos em sentido amplo, desde os modernos videogames até os tradicionais jogos para a emulação de situações de decisão e raciocínio) podem motivar professores e alunos. Novas formas de utilização dos mesmos podem apoiar os processos tradicionais de ensino e aprendizagem, e também a própria avaliação (GEE, 2003; KAPP, 2007). Aqui temos pleno potencial de emprego das novas tecnologias de informação e comunicação pelo professor (software educacional, objetos de aprendizagem, módulos projetados dentro de um modelo de maturidade pedagógica de bases tecnológicas).

Como propostas de metodologias de suporte à didática do professor, em sala de aula, temos a problematização, a exposição dialogada, o trabalho em grupos, a pesquisa, os seminários, os debates, a experimentação, a modelagem e a simulação, a dramatização e a produção coletiva.

\section{CONSIDERAÇÕES FINAIS}

Os fins devem modelar os meios, e não o contrário. O professor tem por fim maior de seu trabalho docente a preparação de um sujeito epistêmico (o aluno) para fatores determinados pela sociedade, pelas políticas públicas, pelo Estado, pelo mercado de trabalho; 
enfim, por algum agente que planeja uma política educacional para determinado grupo social, e de forma política. Por isso deveria o professor realizar o próprio planejamento de ensino e aprendizagem, considerando diversos níveis de atuação, e não apenas o da prática docente cotidiana.

Tishman et al (1999) afirmaram que a distância entre teoria e prática é característica de um mundo que produz grande quantidade de pesquisa, mas pouco aplica em termos reais na sala de aula. Vem daí a sensação de abandono que sente o professor em sua prática, se busca o suporte dos resultados da pesquisa em educação.

O confronto entre as teorias de base do trabalho docente (psicológicas: cognição, motivação, processos de aprendizagem; epistemológicas: a natureza e a construção do conhecimento; pedagógicas: didática, avaliação, metodologia) e o histórico empírico da prática docente (muito forte nas definições dos professores, quando consultados sobre o assunto) nos faz lembrar que o ensino é apenas parte dos causadores de resultados da aprendizagem nos alunos, e não o processo monopolizador da questão.

Esperamos que toda a discussão aqui realizada possa definir parâmetros de melhoria dos processos didáticos do professor da Educação Básica brasileira.

\section{REFERÊNCIAS}

BECKER, Fernando. A epistemologia do professor. 7. ed. Petrópolis: Vozes, 1993.

BECKER, Fernando. A origem do conhecimento e a aprendizagem escolar. Porto Alegre: Artmed, 2003.

BORDENAVE, Juan Diaz; PEREIRA, Adair Martins. Estratégias de ensino-aprendizagem. 9. ed. Petrópolis: Vozes, 1986.

BROOKS, Jacqueline G. Construtivismo em sala de aula. Porto Alegre: Artes Médicas, 1997.

BRUER, J. T. Schools for thought: a science of learning in the classroom. Cambridge: MIT Press, 1993.

CHRISTENSEN, C. M. Inovação na sala de aula: como a inovação de ruptura muda a forma de aprender. Porto Alegre: Bookman, 2009. 
COORDENAÇÃO DE APERFEIÇOAMENTO DE PESSOAL DE NÍVEL SUPERIOR (CAPES). Capes 60 anos: revista comemorativa. Brasília: CAPES, 2011.

ERNELING, Christina E. Towards discursive education: philosophy, technology and modern education. Cambridge: Cmabridge University Press, 2010.

FREIRE, Paulo R. Pedagogia do oprimido. 12. ed. Rio de Janeiro: Paz e Terra, 1983.

GEE, J. P. What video games have to teach us about learning and literacy. New York: Palgrave Macmillan, 2003.

KAPP, K. M. Gadgets, games, and gizmos for learning: tools and techniques for transferring know-how from boomers to gamers. San Francisco: John Wiley and Sons, 2007.

LOWMAN, J. Mastering the techniques of teaching. 2. ed. San Francisco: Jossey-Bass, 1995.

MORIN, Edgar. O método III: o conhecimento do conhecimento/1. 2. ed. Mem Martins: Publicações Europa-América, 1996

PAPERT, S. Mindstorms: Children, computers and powerful ideas. Brighton: Harvester Press, 1980.

PERRENOUD, Philippe. Construir as competências desde a escola. Porto Alegre: Artes Médicas Sul, 1998.

PERRENOUD, Philippe. Dez novas competências para ensinar. Porto Alegre: Artes Médicas Sul, 2000.

PIAGET, Jean. A epistemologia genética. 2. ed. Petrópolis: Vozes, 1973.

PIAGET, Jean. Para onde vai a educação. Rio de Janeiro: José Olympio, 1975.

POLANYI, Michael. Personal knowledge. Chicago: The University of Chicago Press, 1974.

POLANYI, Michael. The tacit dimension. Chicago: The University of Chicago Press, 2009.

POPPER, Karl Raimund. A vida é aprendizagem: epistemologia evolutiva e sociedade aberta. Lisboa: Eduções 70, 2001. 
SAVIANI, Demerval. A nova lei da educação: trajetória, limites e perspectivas. 11. ed. Campinas: Editores Associados, 2008.

SOFFNER, Renato Kraide. Estratégia, conhecimento e competências. Piracicaba: Degáspari, 2007.

TAPSCOTT, D. Growing up digital: the rise of the Net Generation. New York: McGrawHill, 1998.

TISHMAN, S.; PERKINS, D. N.; JAY, E. A cultura do pensamento na sala de aula. Porto Alegre: Artes Médicas Sul, 1999.

VENN, W.; VRAKKING, B. Homo zappiens: educando na era digital. Porto Alegre: Artmed, 2009.

VIGOTSKI, Lev S. A formação social da mente. São Paulo: Martins Fontes, 2007. 